\title{
Medical Law and Misrepresentation in the Practice of Homeopathy and Alternative Medicines in Ghana: Lessons learnt in studying Law \& Practicing Holistic Medicine
}

Raphael Nyarkotey Obu*

LLB Law Student, Faculty of Law, Governance and International Relations, Kings University College, Ghana

DOI: $10.36348 /$ sijlcj.2020.v03i04.004 $\quad$ | Received: 24.03 .2020 | Accepted: 01.04 .2020 | Published: 09.04 .2020

*Corresponding author: Raphael Nyarkotey Obu

Abstract

Tort is a very interesting aspect of civil law that seeks to provide remedy for injuries and non-pecuniary losses people experience as a result of the actions or omissions of others. In my study of Tort, I realized that it has so much to do with what goes on in the health sector, especially with regards to hospital-patient relations. It would seem however that its major concern is with the conventional medical sector. For instance, the case of Bolam v Friern Hospital Management Committee (1957) is the locus classicus when it comes to principles of tortious liability and medical practitioners. In that case, the court enunciated a yardstick (which came to be known as the "Bolam Test") that should be used to ascertain whether or not a hospital/medical practitioner had been negligent in the delivery of his duty to a patient. One wonders however, if the "Bolam test" applies or would apply to alternative medicine practice? If not, what is an appropriate standard for measuring tortious liability among practitioners of alternative medicine? Cases of negligence in the context of alternative medicine are very rare in our law reports and there has not been any such case reported in Ghana to the best of my knowledge. Also, the Patient's Rights of the Ghana Health Service (GHS) Charter interestingly asserted that: "The patient is entitled to know of alternative treatment(s) and other healthcare providers within the Service if these may contribute to improved outcomes". This means that alternative treatment is vital in the healthcare sector if it will improve on the quality of life (QOL) of the patient in Ghana. It is therefore vital to know of the court decision on prescribers of alternative medicines if the treatment goes sour. Also being a law student and practitioner of Naturopathy and Holistic Medicine, The Carlill V Carbolic Smoke Ball (1892) in Law of Contract case became my favorite partly because it falls under the umbrella of false claims and the company in question was a homeopathic company. It further signifies the many advertisements and claims made by practitioners of herbal, homeopathy and alternative medicine. Many of the practitioners in Ghana could be held liable if patients understand this principle and take them on for many of their false claims. In a nutshell, studying law has broadened my scope in the Medical field especially in the practice of Naturopathy and Holistic Medicine and I keep asking myself this simple question: How much of alternative and traditional medicine practitioners would survive if the legal principles were rigorously applied in Ghana?

Keywords: Medical Law, Naturopathy, Holistic Medicine, liability, Homeopathy.

Copyright @ 2020: This is an open-access article distributed under the terms of the Creative Commons Attribution license which permits unrestricted use, distribution, and reproduction in any medium for non-commercial use (NonCommercial, or CC-BY-NC) provided the original author and source are credited.

\section{INTRODUCTION}

According to the World Health Organization 2019 report, Traditional and complementary medicine $(\mathrm{T} \& \mathrm{CM})$ is an important and often underestimated health resource with many applications, especially in the prevention and management of lifestyle-related chronic diseases, and in meeting the health needs of ageing populations. Many countries are seeking to expand coverage of essential health services at a time when consumer expectations for care are rising, costs are soaring, and most budgets are either stagnant or being reduced. Given the unique health challenges of the 21 st century, interest in $\mathrm{T} \& \mathrm{CM}$ is undergoing a revival.

The question: what is alternative and complementary medicine? The WHO, 2019 report had this to say:

"The terms "complementary medicine" and "alternative medicine" refer to a broad set of health care practices that are not part of that country's own traditional or conventional medicine and are not fully integrated into the dominant health care system. They are used interchangeably with traditional medicine in some countries" hence, practices such as homeopathy, Naturopathy, Acupuncture, Chiropractic, Yoga etc are 
aliens in the Ghanaian health system and are therefore termed complementary and alternative medicines.

The WHO also states that, Herbal medicines also include herbs, herbal materials, herbal preparations and finished herbal products that contain, as active ingredients, parts of plants, other plant materials or combinations thereof. In some countries, herbal medicines may contain, by tradition, natural organic or inorganic active ingredients that are not of plant origin (e.g. animal and mineral materials).

It further defined indigenous traditional medicine as the sum total of knowledge and practices, whether explicable or not, used in diagnosing, preventing or eliminating physical, mental and social diseases. This knowledge or practice may rely exclusively on past experience and observation handed down orally or in writing from generation to generation. These practices are native to the country in which they are practiced. The majority of indigenous traditional medicine has been practiced at the primary health care level, but are these practitioners aware of their liability?

Before enrolling to study LLB law at the Kings University College, Ghana, one of the few accredited and recognized law universities, I might have thought of certain issues as they came up in my practice of Naturopathy and Holistic Medicine from an entrenched point of view, or maybe not at all. However, I now know that, law itself is not definite and the practice of law and holistic Medicine is a battle field in the advanced countries. This time, I started thinking through the rules right away. Law school gets you to start thinking about the logical extensions, limitations, and ambiguities of rules as soon as you hear about those rules. You start thinking of various problems that come up in your life or practice and your friend's lives from a legal standpoint. Even my field of medical practice in holistic medicine has changed drastically.

In law of tort II which primarily deals with negligence cases, I realized the many law suits against medical practitioners, alternative medicine practitioners and manufacturers of Natural Products. However, in Ghana, the practice is a developing one and one could just see from the claims of the practitioners many misrepresentations that could be held liable against them, yet no one takes them on. This could be due to either ignorance on the part of the patients or the cost of legal services. Also most of these practitioners are not even aware of the legal implications of false claims they advertised on the airwaves. The more I learn in law school, the more aware I am that there is so much substantive law a lawyer must know about in order to best represent his or her client and especially in my medical practice in holistic medicine. Medical law is underdeveloped also in Ghana and the medical lawyer must have extensive knowledge in the field of holistic medicine to represent the clients.

\section{National policy on Traditional \&Complementary Medicine}

In Ghana, there is a national policy on T\&CM, titled Policy of Traditional Medicine Development in Ghana, which is also integrated into the Policy on Protection of Genetic Resources. The Traditional Medicine Practice Act of 2000 (TMP Act) constitutes the national regulation on T\&CM. This Act established the Traditional Medicine Practice Council (TMPC) as a regulatory body based on ACT 575. The Traditional and Alternative Medicine Directorate under the Ministry of Health $(\mathrm{MoH})$ serves as the national office for T\&CM. A national expert committee exists and comprises stakeholders from the $\mathrm{MoH}$, academia, civil society, the Noguchi Memorial Institute for Medical Research, the Centre for Scientific Research into Plant Medicine and the Ghana Federation of Traditional Medicine Practitioners Association. The Centre for Scientific Research into Plant Medicine in Ghana functions as the national research institute for T\&CM. National laws and regulations on T\&CM include the Food and Drugs Law of 1992, the Pharmacy Act of 1995 and the TMP Act. There are also policy guidelines on intellectual property rights related to plant genetic resources. As at end 2016, there is no government or public research funding for T\&CM. In 2011, a national plan for integrating T\&CM into national health service delivery was formulated. A consumer education programme for self-health care using T\&CM was introduced in 2000.

\section{Regulatory status of herbal medicines}

The WHO, 2019 report asserted that, Herbal medicines are regulated partly in the same way as conventional pharmaceuticals, in the category of herbal medicines. Regulations were updated in 2012. The new Pharmacy Act and the Food and Drugs Law are yet to classify medicines and provide definitions. Herbal medicines are sold with medical, health and nutrient content claims that are regulated by laws, but those laws are weakly enforced. The Ghana herbal pharmacopoeia (2nd ed., 2007) is the national pharmacopoeia and the Ethnobotanical and Floristic Studies is also used; these publications are authoritative and respected but not legally binding. The Nigerian herbal pharmacopoeia (2008), the African herbal pharmacopoeia (1995) and the WAHO's West African pharmacopoeia are also referred to. As of 2012, 120 national monographs were issued as part of the series, Monographs on medicinal plants of Ghana. The Training manual for traditional medicine practitioners was issued in 2002. The Good Manufacturing Practice (GMP) regulations that apply to herbal medicines are the same as that for conventional pharmaceuticals.

Manufacturers of herbal medicines are required to adhere to the manufacturing information in pharmacopoeias and monographs, to ensure their quality. To ensure compliance, pre-registration inspections and testing, usually executed by the Food 
and Drugs Board of Ghana, are statutory requirements. Chronic, sub chronic and organ-specific toxicity profiling is part of the safety assessment of herbal medicines. Herbal medicines are registered with the Food and Drugs Board; 375 out of 500 herbal medicines still maintain their registration. These were last updated in 2016. Ghana has kept a national list of 190 herbal medicines since 2008 and these are selected based on traditional use of the herbal medicines, clinical data, long-term historical use, laboratory testing and registration. Two herbal medicines were selected for the National Essential Medicine List (NEML) (as at end 2016). The market surveillance system for safety of medicines has included herbal medicines since 2000 . Herbal medicines are sold in pharmacies as prescription and non-prescription medicines, in shops that sell chemicals, in special outlets such as herbal medicine shops and by licensed practitioners in small clinics.

\section{Practices, providers, education and health insurance} According to an MoH study in 1998 and WHO data from 2009, 60-79\% of the population in Ghana uses indigenous TM. Data obtained from the Tracking Adaptation and Measuring Development (TAMD) issues from 2004 to 2006 provide estimates of population use for T\&CM practices of $1-19 \%$ for each of the following practices: acupuncture, ayurvedic medicine, chiropractic, homeopathy, naturopathy, osteopathy, therapeutic massage, traditional Chinese medicine and Unani medicine. Herbal medicines are used by $80-99 \%$ of the population. Indigenous TM providers are regulated under the national laws, which are enforced at the level of the TMPC, zonal offices, city councils and community-level associations. Providers of acupuncture, ayurvedic medicine, chiropractic, herbal medicines, homeopathy, naturopathy and traditional Chinese medicine are regulated at the national level. Regulations for T\&CM practitioners were updated in 2016. T\&CM providers practice in private clinics. Agencies of the $\mathrm{MoH}$, such as the Food and Drugs Board and the TMPC, issue the relevant $\mathrm{T} \& \mathrm{CM}$ license or certificate that providers require to practice.

The Kwame Nkrumah University of Science and Technology (KNUST) offers a 4-year bachelor's of science programme in herbal medicines. The programme started in 2001, and the first batch of "medical herbalists" graduated in 2005. Other T\&CM training programmes that the Government officially recognizes include apprenticeships with $\mathrm{T} \& \mathrm{CM}$ providers; a specialized training programme for acupuncture where, after completion, the student receives a certificate or licence; and a training programme for indigenous TM practitioners. Also the Nyarkotey College of Holistic Medicine established in 2017 is also recognized and accredited to offer two-year Professional program in Naturopathy and Holistic Medicine by the Traditional Medicine Practice Council of the Ministry of Health in the area of alternative medicine. The college is on the process to start offering the Doctor of Naturopathy and Holistic Medicine and other alternative medicine programs.

According to a report from the $\mathrm{MoH}$, based on a census of TMPs, 20000 indigenous TM providers practice within Ghana. The TMPC's national register of T\&CM providers for 2009 included 12 acupuncture providers, six ayurvedic medicine providers, six chiropractic providers, 25000 herbal medicine providers, 40 homeopathic medicine providers, 10 naturopathic medicine providers, four osteopathic providers and 12 traditional Chinese medicine providers. Private organizations provide the health insurance under which indigenous TM is covered. As of 2012, other T\&CM practices were partially covered by both Government agency and private organizations. Partial private coverage is available for chiropractic, herbal medicines, naturopathy and traditional Chinese medicine. As at end 2016, T\&CM services are not reimbursed by public health insurance. There are many liabilities of these practitioners, however, many are unaware.

In the medical world, certain events that happen in the care of a patient are called sentinel events. These are unexpected events that cause serious physical or psychological injury or harm to a patient. These are usually procedure-based events such as operating on the wrong extremity or inadvertently puncturing an organ when doing a procedure. One would imagine that the delineation between what is and what is not a sentinel event is pretty straightforward. Sometimes it is, sometimes it isn't. In the career of a neurosurgeon or orthopedic surgeon, there is a $20 \%$ chance of operating on the wrong side extremity, wrong finger, or wrong level of spine.

\section{Contract and Medical Law}

In law of contract, the 1892 case of Carlill v Carbolic Smoke Ball Company, which related to an advertisement placed in the Pall Mall Gazette promoting the use of the defendant's carbolic smoke ball to prevent a person from contracting influenza, and promising $£ 100$ to any user who did get the flu is a locus classicus and was my favorite law case.

The facts of the case conjure up a Punch-like cartoon image of a Victorian lady, head covered with a towel, leaning over and breathing in waves of carbolic smoke fumes. The actual text of the advert is part of what makes this case amusing. Every element of it was analyzed during the case. As well as promising a $£ 100$ reward, the company also said that $£ 1,000$ had been deposited with Alliance Bank of Regent Street "showing our sincerity in the matter". It also said: "During the last epidemic of influenza many thousands of carbolic smoke balls were sold as preventatives of this disease, and in no ascertained case was the disease contracted by those using the carbolic smoke ball. 
"One carbolic smoke ball will last a family several months, making it the cheapest remedy in the world at the price, 10s. post free." On the faith of this advert, Mrs Carlill bought and used the smoke ball as directed for two months, but in January 1892 nevertheless did contract the flu. She then bravely embarked on a claim for the $£ 100$ promised in the advert $-£ 100$ in those days being a very tidy sum indeed.

The defendants unsuccessfully argued that the advert was a mere "advertising puff", which was never intended to create a legal relationship with any individual purchaser of a smoke ball in reliance on it.

Secondly, they argued that if a contract was thereby created, it was void as a wagering contract. They also put forward the argument that it was an illegal form of contract insurance.

However, Mrs Carlill's fortitude paid off - she succeeded in both the English high court and court of appeal, and recovered the $£ 100$ plus her legal costs. Both courts held the reliance by Mrs Carlill on the advert established a contract by the defendants to pay her $£ 100$ in the event that happened.

The Carlill case became my favorite partly because it falls in the jurisdiction of false claims and the company in question was a homeopathic company. It signifies the many advertisements and claims made by practitioners of herbal, homeopathy and alternative medicine. The sui generis is that it exemplified a number of legal principles relating to the formation of a contract, which can be expressed in simple terms as an offer by one party that is accepted by another where something of value (ie consideration) passes between the two parties. Many of the practitioners in Ghana could be held liable if clients understand this principle and take them on for many of their false claims.

\section{QUACKERY and Medical Practice}

The case in carlill is a typical manifestation of quackery. In order for a quack to be found to be offering a wrong medication there had to be a right way of treating it. For instance, the current COVID-19 pandemic had no treatment pathway. What did Conventional doctors have to offer? As it stands, there is no medical science decision or any medicine that can still cure nor entirely avert infection with the coronavirus, hence, any claim of capacity to do so by anyone would clearly be incorrect. What is now done is to target easing the symptoms of affected patients. For instance, in Ghana, one could just chance on advertisement such as offers to make your breasts (if you're a woman) bigger or firmer by applying an emulsion are suspect, promising penile enlargement, cancer cure, result guaranteed in a given time frame etc just to siphon monies from the already distressed patients.
The book Breast Care (1983) says: "There are no proven methods to create larger breasts, as some advertisements may claim "

\section{Medical Jurisprudence}

Medicine and the law do not always work in harmony. Medical jurisprudence, also called Legal Medicine, science that deals with the relation and application of medical facts to legal problems. There are hearsay scenarios where alternative practitioners prescribe pharmaceutical medications which is against their standard. Alternative Medicine Practitioners should not veer into conventional medicine where he received no formal training. This may create a huge liability to the practitioner. A locus classicus case here is the Poonam Verma v. Ashwin Patel \& Ors which had to do with who is a quack in medical field. In Poonam Verma v. Ashwin Patel and Ors., 1996, it was held that the doctor who was entitled to practice in homeopathy only, was held under a statutory duty not to enter the field of any other system of medicine. Since he trespassed into a prohibited field and prescribed medicine to the patient causing the death, his conduct held amounted to negligence per se actionable in civil law.

The Hon'ble Supreme Court of India, further held that: "A person who does not have knowledge of a particular System of Medicine but practices in that System is a Quack and a mere pretender to medical knowledge or skill, or to put it differently, a Charlatan." In this case, the doctor in question holds Diploma in Homeopathic Medicine and Surgery (DHMS) and registered under Bombay Homeopathic Practitioners Act, caused the death of a patient due to administration of Allopathic medicine, the Supreme Court held him being not qualified to practice Allopathy.

In view of the above landmark judgment, it is stated that the person who possesses recognized qualification / knowledge of a particular system of medicine is only authorized to practice in that particular system of medicine. If a person practices in any other system of medicine of which he does not possesses recognized qualification / knowledge, then that person would be considered as a quack i.e. a mere pretender to medical knowledge or skill, or a charlatan.

The Supreme Court further delved into the issue of what is medical negligence. In the context, the Court held as under:

I. Negligence has many manifestations - it may be active negligence, collateral negligence, comparative negligence, concurrent negligence, continued negligence, criminal negligence, gross negligence, hazardous negligence, active and passive negligence, willful or reckless negligence or Negligence per se." 
Negligence per se is defined in Black's Law Dictionary as under:

Negligence per se-Conduct, whether of action or omission, which may be declared and treated as negligence without any argument or proof as to the particular surrounding circumstances, either because it is in violation of a statute or valid municipal ordinance, or because it is so palpably opposed to the dictates of common prudence that it can be said without hesitation or doubt that no careful person would have been guilty of it. As a general rule, the violation of a public duty, enjoined by law for the protection of person or property, so constitutes.

Also in "As laid down by Apex Court in the case Jacob Mathew v State of Punjab (Jacob Mathew case), we feel it is high time that hospital authorities realize that the practice of employing non-medical practitioners such as Doctors specialized in Unani system and who do not possess the required skill and competence to give allopathic treatment and to let an emergency patient be treated in their hands is a gross negligence.

The Supreme Court recently stated in Dr Jacob Mathew's case (1) that in order to make a doctor criminally responsible for the death of a patient, it must be established that there was negligence or incompetence on the doctor's part which went beyond a mere question of compensation on the basis of civil liability. Criminal liability would arise only if the doctor did something in disregard of the life and safety of the patient. Certain directions have also been given in the case.

Also in India, in a questions, AYUSH practitioners prescribing allopathic medicines: Rajya Sabha, information given by the Minister for Health \& Family Welfare, Dr. Anbumani Ramadoss in a written reply to a question in the Rajya Sabha had this to addressed:

The matter regarding qualified practitioners of Ayurveda, Unani, Siddha and Homoeopathy systems prescribing allopathic medicines has been examined in depth by the Hon'ble Supreme Court of India in Civil Appeal No.89 of 1987 Dr. Mukhtiar Chand \& Others versus State of Punjab \& Others [1].

Representations have been received from time to time on this matter and accordingly Department of AYUSH entrusted the study of the contemporary acts on medical practice in the light of judgement of Hon'ble Supreme Court in 1987 Dr. Mukhtiar Chand \& Others versus State of Punjab \& Others and other similar judgements [1]. Drugs can be sold and supplied by a Pharmacist or a Druggist only on a prescription of a Registered Medical Practitioner and who can also store them for treatment of patients.
According to Section 2 (ee) of the Drugs and Cosmetics Rules, 1995, Registered Medical Practitioner means a person -

- holding a qualification granted by an authority specified or notified under Section 3 of the Indian Medical Degrees Act, 1916 (7 of 1916), or specified in the Schedules to the Indian Medical Council Act, 1956 (102 of 1956); or

- registered or eligible for registration in a medical register of a State meant for the registration of persons practicing the modern scientific system of medicine (excluding the Homoeopathy system of medicine); or

- registered in a medical register (other than a register for the registration of Homoeopathic practitioners) of a State, who although not falling within sub-clause (i) or sub-clause (ii) is declared by a general or special order made by the State Government in this behalf as a person practicing the modern scientific system of medicine for the purposes of this Act.

Hon'ble Supreme Court upheld the validity of Rule 2 (ee) (iii) as well as the notifications issued by various State Governments there under allowing Ayurveda, Siddha, Unani and Homoeopathy practitioners to prescribe allopathic medicines.

In view of the above judgment, Ayurveda, Siddha, Unani and Homoeopathy practitioners can prescribe allopathic medicines under Rule 2 (ee) (iii) only in those States where they are authorized to do so by a general or special order made by the concerned State Government in that regard. Practitioners of Indian Medicine holding the degrees in integrated courses can also prescribe allopathic medicines if any State act in the State in which they are practicing recognizes their qualification as sufficient for registration in the State Medical Register.

In view of that, in Dr. Mehboob Alam Vs. State of U.P. and ors. judgenmet by G.P. Mathew, the question that arose was: whether a person having the degree of Bachelor of Unani Medicine and Surgery is entitled to practice modern medicine and to prescribe allopathic drugs.

The petitioner claims that he was awarded the degree of Bachelor of Unani Medicine and Surgery (for short BUMS) by Aligarh Muslim University in the year 1990 and thereafter he completed six month's rotatory internship at A. K. Tibbiya College, Aligarh Muslim University. Aligarh and in the District Hospital, Sahjahanpur. His name has been entered in the register maintained by Board of Indian Medicine on 29-9-1992. On the basis of the aforesaid degree and registration of the name, the petitioner contends that he is entitled to practice as a doctor and prescribe allopathic medicines as well apart from unani medicines. 
It was held that neither it is averred in the writ petition nor it has been urged that the petitioner is enrolled on a State Medical register as defined in Section 2(k) of Indian Medical Council Act, 1956 and, therefore, he is not entitled to practice modern scientific medicine or to prescribe allopathic drugs. Learned counsel has also referred to certain provisions of Drugs and Cosmetics Rules but in our opinion they are wholly irrelevant as they deal with import manufacture, distribution and sale of drugs and they neither confer nor deal with the right to practice medicine. The writ petition lacks merit and is hereby dismissed. The stay order staying the arrest of the petitioner, as extended from time to time, is vacated.

Another case involving the recognition of the practice of electrohomeopathy was dismissed in the case of Electrohomoepathic Doctor's Association Vs. State of Punjab and Ors.

\section{Liabilities of the Alternative Medicine Practitioners}

Tort law is interesting and I realized that the law programs focus especially on negligence in conventional medical sector. For instance, the 'Bolam test' is the locus classicus that centered or apply to medical practitioners. I could remember I drew my lecturer attention to other area of medicine such as alternative medicine and whether the 'Bolam Test' applicable to them. So the question: Is the 'Bolam test' applicable to alternative medicine practice? If not, what is an appropriate standard? Cases of negligence in the context of alternative medicine are very rare in the legal record, and there has not been any such case reported in Ghana as I do know. Interesting there is one leading case that refers to these practitioners (Shakoor $v$ Situ) which is a common law case. Article 11(e) also emphasis the common law as part of the laws of Ghana in the 1992 constitution. The Ghana Health Service (GHS) Patients Charter was introduced in 2002.

This Charter is made to protect the Rights of the patient in the Ghana Health Service. It addresses:

i. The Right of the individual to an easily accessible, equitable and comprehensive health care of the highest quality within the resources of the country.

ii. Respect for the patient as an individual with a right of choice in the decision of his/her health care plans.

iii. The Right to protection from discrimination based on culture, ethnicity, language, religion, gender, age and type of illness or disability.

iv. The responsibility of the patient/client for personal and communal health through preventive, promotive and simple curative strategies.

The Patient's Rights of the charter interestingly asserted that:

The patient is entitled to know of alternative treatment(s) and other health care providers within the Service if these may contribute to improved outcomes.
This means that alternative treatment is vital in the healthcare sector if it will improve on the quality of life of the patient in Ghana. It is therefore vital to know of the court decision on prescribers of alternative medicines if the treatment goes sour.

The courts have explained that CAM practitioners are not to be judged by the standards of a practitioner of orthodox medicine. As emphasized in Shakoor (Administratrix of the Estate of Shakoor) v Situ (t/a Eternal Health Co) [2001] 1 W.L.R. 410 [2], "the fact that the patient has chosen to reject the orthodox and prefer the alternative practitioner is something important which must be taken into account. Why should he later be able to complain that the alternative practitioner has not provided him with skill and care in accordance with the standards of those orthodox practitioners whom he has rejected?" (per Bernard Livesey QC at 416). For that reason, the skill and care expected of them are those of a reasonably competent practitioner of their particular art who is practicing in accordance with the standards required in the UK. However, if the prevailing standards are regarded as deficient in this country having regard to the risks which were not but should have been taken into account, the courts may find a practitioner whose patient has suffered an injury as a consequence of the treatment provided, to be negligent.

The position means that CAM practitioners are, like orthodox medical practitioners (as stated Bolam v Friern Hospital Management Committee [1957] 1 W.L.R. 582 [3] and Bolitho (Deceased) v City and Hackney HA [1998] A.C. 232) [4], allowed to define their own standard of care. However, this comes with an important caveat: they are under a duty to ensure that the remedy prescribed or applied would not cause harm to the patient. Importantly, this duty can be discharged only by keeping abreast of risk information published in orthodox medical journals. This does not imply that they must take a range of publications themselves. All that is required is for them to join an organization which searches the relevant literature and reports back to its members. Thus notwithstanding the fact that there is currently no legal obligation for a CAM practitioner to be a member of a professional organization, one who does not do so "will not have discharged his duty to inform himself properly and may act at his peril"

Interestingly, in Ghana, most of the practitioners do not belong to any recognize organization, not to talk of scientific publications in orthodox medical journal. The question is how do they know or get abreast with recent trends in their practices?

The Principle as defined in Shakoor v Situ according to Tse et al., 2006 [2]

i. The 'Bolam test' does not apply in this context. 
ii. The practitioner is not to be judged by the standard acceptable to a body of opinion of his fellow Chinese herbal medicine practitioners.

iii. A practitioner of alternative medicine cannot be judged by the standards of orthodox medical practitioners since he is not declaring himself to be or representing himself as a practitioner of such medicine and his patients have chosen to reject the orthodox approach.

iv. The duty of the practitioner in alternative medicine is to ensure that the remedy prescribed is not merely believed within the art to be beneficial, but also it is not harmful.

v. In order to discharge his duty, an alternative medicine practitioner should keep abreast of the relevant publications in the orthodox medical and pharmacological fields in order to be aware of published reports of adverse reactions to remedies or their components.

vi. The Court recommended that practitioners to subscribe to an association that arranged to search the relevant literature.

vii. The Court gave this warning: "If he does not subscribe to such an association, the practitioner will not have discharged his duty to inform himself properly and may act at his peril".

\section{Does it apply to the Medical Practitioner veering into Alternative Medicine?}

According to Tse et al., 2006 [9], the position in Shakoor v Situ does not involve a physician using alternative medical approaches. However, if an alternative medical practitioner is required to be sufficiently knowledgeable about developments in the orthodox field that may impact on alternative treatments, it must follow that a physician must be at least as knowledgeable about developments in his primary field that may affect an alternative treatment modality he wishes to recommend to a patient.

\section{The law in Samoa}

Let us now consider what the law in Samoa asserts about traditional healers. Traditional healers are recognized by the laws of Samoa. Under the interpretation section of the Healthcare Professions Registration and Standards Act 2007, 'healthcare professional' means any person who is registered or entitled to be registered under that Act and any allied healthcare professional regulated by any of the Professional Acts. Section 21 of the Act defines allied health professions as including traditional healers. The Healthcare Professions Registration and Standards Act 2007 gives traditional healers the same recognition as medical practitioners.

These traditional healers share the medical liability of qualified medical practitioners or doctors. This was demonstrated in Samoa in the case of Police $v$ Lavasi'i [5].
In this case, the judge asserted that, the deceased was sick with green discharge from a lump in her breast. She was bedridden and her mother-in-law contacted a traditional healer to see her. This was the family's first attempt to engage Sela, a traditional healer, seeking help for the deceased's illness. Sela, as noted by the judge in his judgment, had inherited her traditional healing skills from her ancestors. Sela succeeded in treating the deceased for the first two days; the patient found comfort and could sleep well. On the third day of the treatment Sela requested that the family boil water and put it in a container so that the deceased could sit on it. Sela was assisted by her husband Felaiai, who brought in leaves and herbs for the treatment. The water was boiled with herbs and leaves and placed in a container and the deceased was made to sit on it. The deceased complained about the heat and was then removed from the container. That night her condition worsened and she was taken to the hospital for the first time. She died that night at the hospital.

The family of the deceased complained and manslaughter charges were laid against Sela and her husband for the death; upon post mortem, one of the causes of death was first-degree burns on the deceased. The judge noted that the 'not guilty' verdict for manslaughter by the assessors was a reflection of total rejection by the assessors of the attempt by the family of the deceased to place total blame on the two defendants for the death. However, it has to be noted that the judge found the two guilty on lesser charges.

The judge had this to say:

[w] hen the defendant Sela was requested to treat the deceased, the family knew she was a recognized traditional healer. Indeed, she had treated and taken care of the deceased's mother in law in her own home free of charge for a whole week before she was requested to attend to the deceased. Those who normally come before this court charged with assault causing actual bodily harm, usually have the malicious intent to cause injury at the time they assault or force is applied. This was not the case here. For three days the two defendants paid for their own transport to travel to Faleasiu and back to Saleimoa, to treat free of charge the deceased. The traditional treatment was done in the open, in the presence of family members. For the first two days of treatments, the deceased found comfort and her family expressed appreciation to the defendants. After the third treatment which led to the death, total blame was placed on the two defendants. The kindness displayed by the two defendants on two previous occasions was promptly forgotten.

The judge gave recognition to the efforts of the two accused to try to heal the deceased. However, the judge then proceeded to work out the penalty of the two accused. The judge found that Felaiai, Sela's husband, was not a traditional healer but had simply accompanied 
his wife to see the sick people and assisted her in collecting herbs and preparing the traditional medicine. The judge went on to note that the post mortem report indirectly revealed the failure and negligence of the deceased's family to seek medical help and care for her ulcerated breast, and that the defendants, who were the only ones to help, had been charged with causing her death.

Justice Vaai noted that it would be against the interests of justice to impose custodial sentences upon the accused persons. The judge discharged Felaiai Lavasii without conviction and convicted Sela Felaiai and placed her on probation for 18 months with special conditions that she attend any programme recommended by the probation service and that she perform 50 hours of community work.

The lesson drawn from this case is that despite the recognition given by the court to the traditional healer for trying to assist, she is still liable under the law for causing or contributing to the patient's death. According to the Lavasi'i case the Samoan courts have shown that consent by the patient or her family does not excuse the traditional healer from any liability. This decision takes away the risk foreseen by the person when consulting a traditional healer for help. However, there was no restriction placed upon Sela to stop her from carrying on her practice as a traditional healer.

\section{The law in Solomon Island}

Traditional or herbal doctors are known to be very popular in the Solomon Islands and they regard their practice as private and personal. A number of cases have gone to court in the Solomon Islands where the judges have made reference to traditional or custom healers. In the case of Tahinao $v$ Regina [6], a case where the use of custom medicine by traditional healer went wrong, Justice Kabui stated:

Traditional medicine is part of the cultures in Melanesia, including Solomon Islands. There are custom or traditional healers in many cultures in the world. In Melanesia, there are two types of custom treatment for ills that befall people in society. The first is the treatment for magical spells that affect people and are sick because of bewitchment by other people. The second is the treatment for ordinary sickness which may respond readily to treatment by medical herbs administered by custom practitioners who do not have any form of recognized formal qualification. Some custom medicine practitioners do combine the ability to administer treatment for magical spells as well as treatment for ordinary sickness, depending on the diagnosis prevailing at a particular time in a particular case. This case is about the practice of custom medicine which allegedly went wrong

The judge went on to say that methods used by traditional healers in treatment of patients by custom medicine are standard and there is no touching of the genitalia or private parts of the patient except by a person of the same sex in cases where it is absolutely necessary. Justice Kabui went on to state that massaging, smoking the affected parts of the body, drinking a prepared solution from a cup or receptacle or washing the external parts of the body with the medicine solution are the standard methods of treatment for men and women alike in the Solomon Islands.

Justice Kabui also stressed the traditional healer (doctor) and patient relationship in this case. In a traditional healer (doctor) patient relationship, the traditional healer occupies a dominant position and any treatment the traditional healer administers is accepted without question by the patient, due to the simple reason that the patient wants to recover as soon as possible. The patient does not investigate the professional background of the traditional healer (doctor) or his or her credibility as a practicing healer of sickness. The traditional healer (doctor) is taken for granted to do right to his patients. The judge stated that the patient believed the healer and the belief created confidence. That confidence created the willingness to submit to whatever treatment the healer was to administer. The submission to treatment in this case was in fact consent in the belief that the treatment received was genuine, and in custom medicine, correct.

So in a nutshell, in the Solomon Islands traditional healers are given recognition; however, if they do commit any indecent acts with the patient, the law deals with them in the same way as any ordinary person in an indecent assault or rape case. However, consent may be an issue here as the patient usually consents to whatever treatment the healer administers. So the question that would arise is why should the traditional healer bear the liability when the victim took the risk?

According to Sofia Shah article titled liability of traditional healers where she asked many questions for instance,

I. Should the traditional healer be liable under the law of negligence?

II. What standard of care would be fit for the traditional healer to comply with?

III. In the case of healers who have no formal qualifications, should they be held liable if a treatment backfires?

IV. They do not advertise themselves as healers but people still go to them for healing and custom medicine.

V. They do not perform the traditional healing methods unless they are invited to do so.

VI. The patient goes to them and wants them to perform rituals or treatment knowing very well that this person is not a qualified medical practitioner. 
VII. So the patient carries the risk of the result as they can foresee the risks involved in the treatment.

VIII. The issue that arises is whether a traditional healer in Solomon Islands will be liable under the law if his or her medicine makes the patient's condition worse or even in a case where the patient dies as illustrated in the Livasi'i case from Samoa.

Two of the leading cases in the Solomon Islands in which a person fakes to be a traditional healer resulted in the pretender being prosecuted for false pretenses. In the cases of Regina $v$ Tebounapa and Regina $v$ Sisiolo, the accused pretended to be a traditional healer and sexually abused the patients. The accused portrayed himself as a traditional healer, when people heard about it, they went to him. The accused was charged with rape under the Penal Code and the court sentenced him to a term of imprisonment, as the sexual acts were clearly exceptions to the standard practice in custom medicine. Consent of the patient did not relieve the traditional healer of his liability.

\section{Misleading Advertisement}

Prohibited sale of drugs, herbal medicinal products, cosmetics, medical devices and other household chemical substances.

In Ghana, Part seven (7) sections 111, 112, 113, 114 of the Public Health Act, 2012, Act 851 of the Food and Drugs Authority(FDA) states that:

Section 111

A person commits an offence if that person sells a drug, herbal medicinal product, cosmetic, medical device or household chemical substance which

(a) Has in or on it a substance that may cause injury to the health of the user when the article is used

(i) According to the directions on the label accompanying the article; or

(ii) For a purpose and by a method of use that is customary or usual;

(b) Consists in whole or in part of a filthy, rotten, decomposed or diseased substance or of a foreign matter likely to cause injury;

(c) Is adulterated; or

(d) Is prepared, preserved, packed or stored under insanitary conditions.

\section{Standards}

112.

1. Where a standard is prescribed for a drug, herbal medicinal product, cosmetic, medical device or household chemical substance, a person who manufactures, labels, packages, sells or advertises any other substance in a manner that it is likely to be mistaken for that drug, product, cosmetic, medical device or household chemical substance commits an offence unless the substance is the drug, herbal medicinal product, cosmetic, medical device or household chemical substance in question and complies with the prescribed standard.

2. Where a standard has not been prescribed for a drug, herbal medicinal product, cosmetic, medical device or household chemical substance but a standard for the drug, herbal medicinal product, cosmetic, medical device or household chemical substance is contained in a publication specified in the Fourth Schedule, a person who labels, packages, sells or advertises any other substance or article in a manner that it is likely to be mistaken for the drug, herbal medicinal product, cosmetic, medical device or household chemical substance commits an offence.

3. A person who manufactures, labels, packages, sells or advertises a drug, herbal medicinal product, cosmetic, medical device or household chemical substance for which a standard has not been prescribed, or for which a standard is not contained in a publication specified in the Fourth Schedule commits an offence unless the drug, herbal medicinal product, cosmetic, medical device or household chemical substance

(a) Is in accordance with the professed standard under which it is labelled, sold or advertised, and (b) does not resemble, a drug, herbal medicinal product, cosmetic, medical device or household chemical substance for which a standard has been prescribed or which is contained in a publication specified in the Fourth Schedule.

\section{Deception of consumers}

113. (1) A person commits an offence if that person labels, packages, sells or advertises a drug, a herbal medicinal product, cosmetic, medical device or household chemical substance

(a) In contravention of Regulations or Guidelines made under this Part, or

(b) In a manner, that is false, misleading or deceptive or misbranded as regards its character, constitution, value, potency, quality, composition, merits or safety.

(2) For the purposes of subsection (1), a drug or herbal medicinal product is misbranded

(a) If it is so coloured, coated, powdered or polished in a manner that changes the product or if it is made to appear to be of a better or greater therapeutic value than it really is, or

b) If it is not labeled in the prescribed manner, or

(c) If its label or container or anything accompanying the drug or herbal medicinal product bears a statement, design or device which makes a false claim for the drug or herbal medicinal product, or which is false or misleading.

\section{Prohibited advertisement}

Section 114

1. A person shall not advertise a drug, a herbal medicinal product, cosmetic, medical device or household chemical substance to the general 
public as a treatment, preventive or cure for a disease, disorder or an abnormal physical state, unless the advertisement has been approved by the Authority.

2. Despite subsection (1) a person shall not advertise a drug, a herbal medicinal product, medical device or cosmetic for the treatment or cure for diseases specified in the Fifth Schedule.

\section{Registration of homeopathic drug}

Section 124.

(1) A person shall not manufacture, prepare, supply, sell, distribute, export or import a homeopathic drug, unless the homeopathic drug has been registered with the Authority.

(2) The Authority may issue Guidelines for the registration of homeopathic drugs.

With regards to claims of misleading representations in advertising or in the course of practice by health practitioners, the case law suggests that these claims are evaluated based upon the need for high quality scientific evidence. According to Weir et al 2013 [7], "This is no doubt reflective of a view that when dealing with health matters there is a need for good evidence to avoid personal injury.

In an analogous factual circumstance in $A C C C$ $v$ Willesee Healthcare Pty Ltd, the court determined that representations by the respondent about treating allergies through kinesiology and acupressure and thereby being able to cure or eliminate all, or virtually all, allergies or allergic reactions were misleading and deceptive representations, also based upon the expert evidence of Professor Douglass. This conclusion was reached in the absence of other evidence to the contrary.

In Commissioner of Fair Trading, Department of Commerce $v$ Hunter, an injunction was sought against Hunter, who practiced as a naturopath and medical herbalist. The primary focus of the case was in relation to his advertising of 'live blood analysis', which was said to allow diagnosis of ailments instantly and to assist in the treatment of such illnesses that the Commissioner suggested was a misleading representation under the terms of the Fair Trading Act. Also of concern in this matter were the representations made about the qualifications of Mr Hunter and his ability to diagnose and treat serious health conditions. Mr Hunter used the titles 'Dr', 'Doctor of Natural Medicine' and PhD in advertisements as well as words that could suggest he was a medical doctor. As $\mathrm{Mr}$ Hunter was not a medical doctor, these representations were considered to be misleading or deceptive representations. Also deemed to be misleading or deceptive was the representation that he was competent to treat serious illnesses such as high blood pressure and a list of other conditions. Evidence was presented from Professor Eva Raik, a haematologist with extensive qualifications and experience about the efficacy of live blood analysis and the difficulty in ascertaining medical conditions or making therapeutic decisions or diagnosis from that type of study. There was limited evidence produced by Hunter in relation to the evidence basis for this therapy. The court found, on the basis of the expert evidence, that the representations in regard to the value of live blood analysis were misleading or deceptive or likely to mislead or deceive.

The court ordered that $\mathrm{Mr}$ Hunter be permanently restrained from carrying on a business or in any way providing in trade and commerce naturopathy, medical herbalism, herbalism, iridology, hydrotherapy, sports medicine, osteopathy and blood analysis.

In the UK, Simon Singh famously won the libel case brought against him by the British Chiropractic Association. In the US, a patient has accused Stanislaw R Burzynski, a proponent of alternative cancer cures, of swindling her out of nearly $\$ 100,000(£ 63,000)$ by using "false and misleading tactics". The case is ongoing. Also in the US, a woman was awarded $\$ 7.4 \mathrm{~m}(£ 4.7 \mathrm{~m})$ after suffering a stroke following the intake of an herbal supplement.

And this is the big deal, the world's largest homeopathic manufacturer Boiron recently settled for CAD $\$ 12 \mathrm{~m}(£ 7.4 \mathrm{~m})$ after a class action that was brought against it in Canada for selling homeopathic remedies under false pretenses

\section{The Old Test (the "Bolam" Test) for Medical Practitioners}

According to the Bolam test, a Medical doctor would not be found negligent if he had acted in accordance with a practice accepted as proper by a responsible body of medical practitioners. Further, in Sidaway $v$ Board of Governors of the Bethlem Royal Hospital and the Maudsley Hospital [1985] AC 871, it was decided that the Bolam test should be applied in deciding whether a doctor is negligent in relation to disclosure of information for the purpose of seeking consent from a patient. The "Bolam test" is no longer applicable in UK. In this article, I will explore the implications of Montgomery on the new standard for the duty of disclosure owed by doctors to their patients.

\section{The New UK approach - Montgomery (2015) Brief Facts}

In Montgomery, Mrs. Montgomery was a tiny woman with diabetes. Women who suffer from diabetes are likely to have larger babies. In particular, they have an increased risk of 9-10 per cent of shoulder dystocia, meaning that during vaginal delivery the baby's shoulders would be too wide to pass through the birth canal. However, Mrs. Montgomery was not informed of the risk of shoulder dystocia. Sadly, during delivery, 
shoulder dystocia did occur and her baby was deprived of oxygen, resulting in severe brain injury.

Mrs. Montgomery brought a claim against Lanarkshire Health Board, alleging that she should have been advised of the risk of shoulder dystocia associated with vaginal delivery, and the alternative option of delivery by caesarean section ought to have been offered.

The UK Supreme Court's decision in applying the Bolam test, the lower courts rejected Mrs. Montgomery's claim. Mrs. Montgomery appealed to the UK Supreme Court, which eventually ruled that Mrs. Montgomery should have been warned of the risk of shoulder dystocia and provided with the alternative of a caesarean section.

The Supreme Court adopted a more "patientcentered" test. Instead of the idea of "doctors know the best", leaving the medical profession to decide on what and how much should be disclosed to patients, the court acknowledged that a doctor has a duty to disclose to the patient any material risks involved in any recommended treatments, and any alternative treatments. In deciding what amounts to "material risks", the appropriate consideration is not only from the doctor's perspective, but also whether a reasonable person in the patient's position would be likely to attach significance to the risk.

As a result, the long-standing application of the Bolam test no longer applies in UK for cases that involve negligence in disclosure of risk. However, the Bolam test will continue to apply in negligence cases of diagnosis, treatment and the other aspects of medical care.

\section{Defensive medicine at its peak}

Typically, physicians are suspicious of being sued. They practice defensive medicine and go out of their way to write copious notes, dictate exhaustive patient summaries and operative reports. For the practicing physician, all the documentation, paperwork, and reporting is simply exhausting. Sometimes all of the documentation takes up way more time and energy than the actual exam or procedure. It is a sad state of affairs when $90 \%$ of the time allocated to a patient is dedicated to documentation rather than with actual time with the patient. Hence, defensive acts as a defensive barrier for conventional practitioners in order to avert liability from their patients. However, if alternative medicine practitioners would be held as the same standard in negligent cases as medical practitioner, then the law would cripple the practice of alternative healings since they have no defensive mechanisms as their practice is still struggling for recognition. Defensive medicine is the situation in which a doctor practices medicine, either through diagnosis or treatment, not to help the patient, but rather to prevent legal action (a malpractice suit) if a problem occurs.
The doctor goes beyond what is usually necessary for diagnosing and treating the patient so they can ensure they are not missing any unlikely but possible condition. They may perform procedures that the patient wants or expects even if they aren't clinically necessary, to keep the patient satisfied. For these reasons, defensive medicine is said to lead to overtesting and overtreatment. They want to prevent bad outcomes (however unlikely) and to prevent having an angry patient.

There is some data to suggest ordering more tests may reduce law suits. A study published in The British Medical Journal in 2015 looked at a large number of of physicians practicing medicine in Florida from 2000-2009. They found the doctors who ordered the most tests in any given year were substantially less likely to be sued in the following year.

Another aspect of defensive medicine is when a physician or medical practice avoids treating high-risk patients. They cherry-pick patients who are more likely to have good outcomes, or they choose a medical specialty that has less risk of malpractice suits. This can result in the most talented doctors not treating the patients who need their skills the most. There are some dangers to this approach such as:

I. Overtreatment with antibiotics is one example of defensive medicine that endangers everyone. A parent may expect a prescription for antibiotics when she takes her child to the doctor for a cold. The doctor knows it isn't needed, but the mother insists on getting a prescription. The doctor gives in. Now the child's normal bacteria are killed by the antibiotic, leaving only antibiotic-resistant bacteria. As this occurs, again and again, strains such as MRSA develop that are resistant to most antibiotics and can sicken and kill many patients.

II. Appropriate medical treatments such as watchand-wait for some low risk, slowgrowing prostate cancers may not be used because patients demand an active treatment or could sue if there is a poor outcome. The active medical treatment (such as radical prostatectomy, radiation or hormone therapy) is not without risk of injury, death or complications such as incontinence and impotence.

The defense comes with cost to the vulnerable patient. For instance;

I. Doctors who practice in high-risk specialties are most apt to practice defensive medicine. In 2005, one survey showed as many as $93 \%$ were ordering tests, prescribing drugs, or performing procedures in more of an effort to protect themselves rather than protect the patients those measures were taken for. Legislative efforts to cap malpractice awards are one tactic proposed.

II. Defensive medicine is a very large contributor to the rise of healthcare costs in the United States. 
An analysis published in Health Affair in 2018 estimated that defensive medicine adds \$25.6 billion annually. It may contribute as much as $34 \%$ of the annual healthcare costs in the United States.

Alternative medicine is also subjective until it gets the recognized standard, maybe to be developed by the World Health Organization (WHO) [8]. The question is how would practitioners of alternative medicine also practice defensive medicine to avert liability? It is not possible! But something can be done.

\section{Change in Hong Kong}

In Hong Kong, following Sidaway, the Bolam test is applicable and therefore, only the views of the medical profession are considered in determining whether the medical practitioners are negligent in disclosure of risk.

In recent years, patients' groups have advocated their demand for more thorough disclosure of information and proper communications between doctors and patients. To better reflect the change of values of society, the Medical Council of Hong Kong had revised its Code of Professional Conduct (the "Code"). In particular, section 2.10.2 of the Code has been amended to include the consideration of the individuality of each and every patient in the provision of medical service and communication between doctors and patients.

If the UK Supreme Court's decision in Montgomery is followed in Hong Kong, the Bolam test will no longer apply in deciding whether the medical practitioners are negligent in disclosure of risk and consideration must be given from the perspective of the particular patient

\section{CONCLUSION AND RECOMMENDATION}

There are justified concerns expressed by many about the outrageous representations made by some alternative medicine practitioners especially in Ghana on our airwaves, and it is appropriate that these practices and practitioners are dealt with. Some even sell herbal drugs without FDA approval or conducting any toxicological or microbial analysis for the safety of their patients. Interestingly, some sell their herbal drugs for very long time before deciding to conduct toxicological or microbial analysis. Sometimes, the product fails the microbial or toxicological tests yet these practitioners had sold or prescribed the product to many people.

However, Cases dealing with non-health therapy issues indicate that there is no necessity to provide scientific evidence for a representation, rather a court needs to conclude on the balance of probabilities whether there is a reasonable basis for that representation based upon expert evidence.
Alternative medicine Practitioners could be held in negligence cases as the same standard as orthodox practitioner. Also in negligence cases against CAM practitioners, the evidence of expert CAM practitioners is accepted as influential evidence even in the face of other contrary Orthodox Medicine expert evidence as in Shakoor $v$ Situ [2]. So from my legal education and extensive researches in medical law and alternative medicine practice, the big question is "how much of alternative and traditional medicine practitioners would survive if the legal principles were rigorously applied in Ghana? This tells us that the practitioners, promoters or manufacturers of alternative medicines who do not abide by the rules of evidencebased practice are likely to be operating outside the law.

But notwithstanding also, with the reviews and happenings in Australia's approach to medical practitioner's liability, and how England has looked into the area of liability of herbal healers. England's approach towards alternative medicine practitioners may be analogous as Ghana adopts the common law as part of our laws. This is illustrated very well in the case of Shakoor $v$ Situ (t/a Eternal Health Co.).

But as the court held that qualified medical practitioners were available in England and the plaintiff chose alternative practitioner. The Court held in this case that the defendant was not negligent when supplying the plaintiff with the herbal medication. Also, there was implied consent by the plaintiff to take the herbal medicine and a lower standard of care imposed upon the herbal healer. The standard of care would have been higher for a qualified medical practitioner but was lower for the herbal healer. This can be compared with the approach taken by other jurisdiction in relation to qualified medical practitioners where the patient would bear the risk if fully informed of the likely consequences of the surgery. Medical practitioners fulfil their duty as long as they have fully informed the patient of the likely results of the operation. The Shakoor case is a highly persuasive case for Pacific island jurisdictions and I am waiting patiently to see Ghana's law court would one day handle such a case if it does happen.

Also Medical Practitioners and allied health professionals who may wish to practice alternative medicine should ensure these maxims as stipulated by Tse et al., 2006 [9]:

a) They are properly skilled in that particular alternative medical practice;

b) The particular alternative practice is safe;

c) They have taken reasonable steps to ensure that the alternative treatment modality is not contraindicated under orthodox medicine;

d) They have thoroughly reviewed the relevant literature for adverse reports related to the relevant practice; and 
e) They observe the requirements stipulated by the Professional Code and Conduct of their Medical Councils

\section{REFERENCES}

1. Chand, D. M. (1998). Ors. vs. State Of Punjab \& Ors, 7.

2. Shakoor (Administratrix of the Estate of Shakoor) v Situ (t/a Eternal Health Co) [2001] 1 W.L.R. 410

3. Bolam v Friern Hospital Management Committee [1957] 1 W.L.R. 582

4. Bolitho (Deceased) v City and Hackney HA [1998] A.C. 232

5. Police V Lavasi'i [2010] WSSC 20 http://www.paclii.org.

6. Tahinao v Regina [2005] SBHC.
7. Weir, M., Wardle, J., Marshall, B., \& Archer, E. (2013). Complementary and alternative medicine and consumer law. CCLJ-Competition and Consumer Law Journal. https://www.researchgate.net/publication/2597425 75_Complementary_and_alternative_medicine_an d_consumer_law

8. World Health Organization. (2001). Legal Status of Traditional Medicine and Complementary/Alternative Medicine: A Worldwide Review.

9. Tse, J., Chang, W., \& Yeung, C. (2006). Doctors practising alternative medicine--the legal considerations. Hong Kong medical journal= Xianggang yi xue za zhi, 12(2), 164. 